\title{
Pricing Strategy of Multi Channel Supply Chain Based on Manufacturer's Pricing Time
}

\author{
Shusheng Sun \\ School of Management, Wuhan University of Science and \\ Technology \\ Wuhan, 430081, China
}

\author{
Lei Liu \\ School of Management, Wuhan University of Science and \\ Technology \\ Wuhan, 430081, China \\ liulei401658300@163.com
}

\begin{abstract}
In a multi-channel supply chain system, if the retailer increases the direct channel on Internet, the dominant manufacturers are faced with pricing decisions under the consideration of the price sensitivity of the demand in channels. Based on the theory of delayed game theory, this paper analyzes the pricing time of manufacturer's direct channel by using Stackelberg game model. Study found that manufacturers should establish and publish direct prices of direct channels before retailers set retail prices and direct prices. The upfront release of direct price can maximize the profitability of the manufacturer. The study results can provide theoretical basis for the pricing strategy of manufacturers in multi-channel supply chain structure model.
\end{abstract}

Keywords-multi-channel supply chain; the delayed game theory; Stackelberg model

\section{INTRODUCTION}

Due to the rapid development of the Internet, more and more manufacturers and retailers are attracted by the Internetbased direct marketing channels. In the model of multichannel sales, not only manufacturers increase network channels on the basis of traditional retail channels, but retailers also increase the network direct selling channels on the basis of the actual retail sales. Retailers increasing the sales channels, it can break the time limit and location limit they faced when they sale only through the retail entity, but also solve the problems of brand building and marketing cost. Although the increase of new channels will bring a lot of benefits to retailers, it will increase the competitiveness of the market. It has an impact on the demand of the retailers' entity channels and the demand of the manufacturers' direct channels, and it also causes conflicts among the channels.

For it, many researchers have studied the competition strategies of multi channel supply chain from the aspects of supply chain time sensitivity and risk sensitivity to decision making and price competition. For examples, Choi (1991) analyzed three different power structure pricing strategy of multi channel supply chain. The paper first systematically studies the pricing problems of supply chain structure, and provide the basis for the later research of multi channel [1]. Hua, Wang et al. (2010) studied the delivery time and price strategy through the basic game theory method of centralized decision-making and decentralized decision-making model of supply chain, found the impact on channel pricing strategy among the members of the delivery time [2]. Chiang and Chhajed (2003) studied the selection strategy of the supply chain channel in the e-commerce environment, and concluded that even if the Internet direct channel is not profitable, its existence can restrict retailers to make the retail price. Regardless of the impact it to the retail demand, the profits of the whole supply chain is improved. Relying on the customer utility theory [3]. Chiang (2012) qualitatively analyzed the difference between the direct channel and the traditional channel. Besides, he found that that the direct channel has a great influence on the traditional retail channels, and the Internet can improve the overall interests by reducing the double marginal phenomenon of reducing pricing [4]. Tang (2010) discussed the problems of the demand's dependence on retail prices through the study of the mode of the co-existence of sale and operation in supply chain. Through the study and analysis of the influence of channel fairness strategy on manufacturer and retailer, Xin Wei found that manufacturers do not care whether retailers are obtained the corresponding channel fairness when a product market share is not large enough, otherwise they do [5]. Ji Leilei (2015) found that the entire supply chain profit is optimal in the centralized decision-making, through the analysis and comparison of the supply chain members' optimal pricing strategy and revenue situation in centralized decision-making and decentralized decision-making [6]. Kenji Matsui(2017)discussed a twochannel supply chain system manufacturer and retailer by using observable delayed game theory framework in noncooperative game theory. Taking the retailer's service into consideration, he also studied when manufacturers in the supply chain should publish their wholesale prices and direct prices. Finally, he came to the conclusion that the manufacturer should set the direct price before the retailer sets the retail price so that the profit maximization can be achieved [7].

In summary, the research of multi-channel supply chain mainly focuses on pricing strategy and coordination mechanism, and the manufacturers' pricing time in the network direct channel and traditional retail channel in the non-cooperative state of manufacturer and retail is not taken into consideration. Moreover, in a typical dual channel supply chain, manufacturers sell goods not only through retailers, but also through direct channels such as the Internet. But retailers 
sell goods only through retail channels [8]. Based on that, this paper will study the time of direct pricing and wholesale price of manufacturers in multi-channel supply chain. Based on the theory of delayed game, a non-cooperative game model between manufacturer and retailer is established, discussing the influence of time point of manufacturer's direct price on manufacturer's profit.

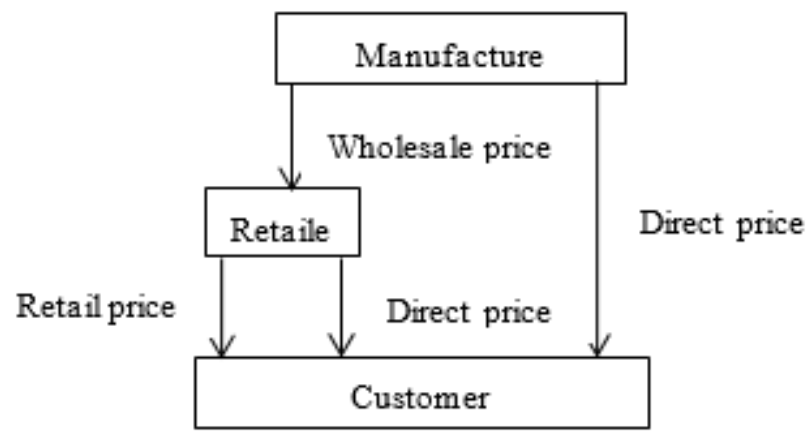

Fig. 1. Channel on manufacturer's profit will be discussed.

\section{PROBLEMS DESCRIPTION AND MODEL BUILDING}

The problems studied in this paper are shown in Figure 1. In a multi-channel supply chain where a single manufacturer and a single retailer exist, the manufacturer produces only one commodity and the retailer sells the product supplied by the manufacturer. Manufacturers is dominant in the entire supply chain. Supposing that the marginal cost of the manufacturer's production is c. The manufacture wholesales the products to retailer at price $\mathrm{w}$, and it sales directly through manufacturer at direct price $\mathrm{P} 3$; and the retailer determines their retail prices $\mathrm{P} 1$ and direct prices $\mathrm{P} 2$ according to the wholesale prices. Based on that, we derive the demand function for the manufacturer's direct channels, retailers, retail channels, and retail direct channels as follows:

$$
\begin{aligned}
& d_{1}=\theta_{1} a-s_{1} p_{1}+\beta p_{2}+\beta p_{3} \\
& d_{2}=\theta_{2} a-s_{2} p_{2}+\beta p_{1}+\beta p_{3}
\end{aligned}
$$

$$
d_{3}=\left(1-\theta_{2}-\theta_{1}\right) a-S_{3} p_{3}+\beta p_{1}+\beta p_{2}
$$

a (a>0) indicates the total demand of the market;

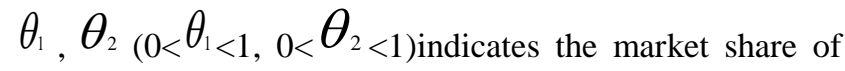
the retailer's direct and retail channels; $S_{1}, S_{2}, S_{3}$ indicates the price elasticity within the channel;

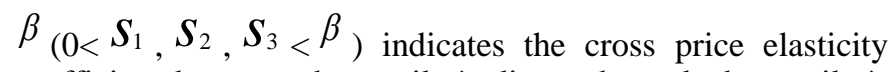
coefficient between the retailer's direct channel, the retailer's direct channel and the manufacturer's direct channel (to simplify the calculation, it is written as $\beta$ ). Any channel has its minimum demand, that is, the demand will not be 0 . So :

$$
\begin{aligned}
& \theta_{1} a-s_{1} p_{1>0} \\
& \theta_{2} a-s_{2} p_{2>0,} \\
& \left(1-\theta_{2}-\theta_{1}\right) a-s_{3} p_{3>0,}
\end{aligned}
$$

From that we can come to the profits of manufacturers $\Pi$ and the profits of retailers $\pi$ :

$$
\begin{aligned}
& \Pi=(w-c)\left(d_{1}+d_{2}\right)+\left(p_{3}-c\right) d_{3} \\
& \pi=\left(p_{1}-w\right) d_{1}+\left(p_{2}-w\right) d_{2}
\end{aligned}
$$

According to the theory of delayed games, it is important whether the players who moves first gets more benefits [9]. As shown in Figure 2, from the manufacturer's point of view, we discuss the impact of the timing of the manufacturer's announcement of direct price P3 on the profits in three cases. (Both the manufacturer and retailer should decide the direct price after the wholesale price is announced by manufacturers. So the order of the announcement of direct price and wholesale price is no taken into consideration).

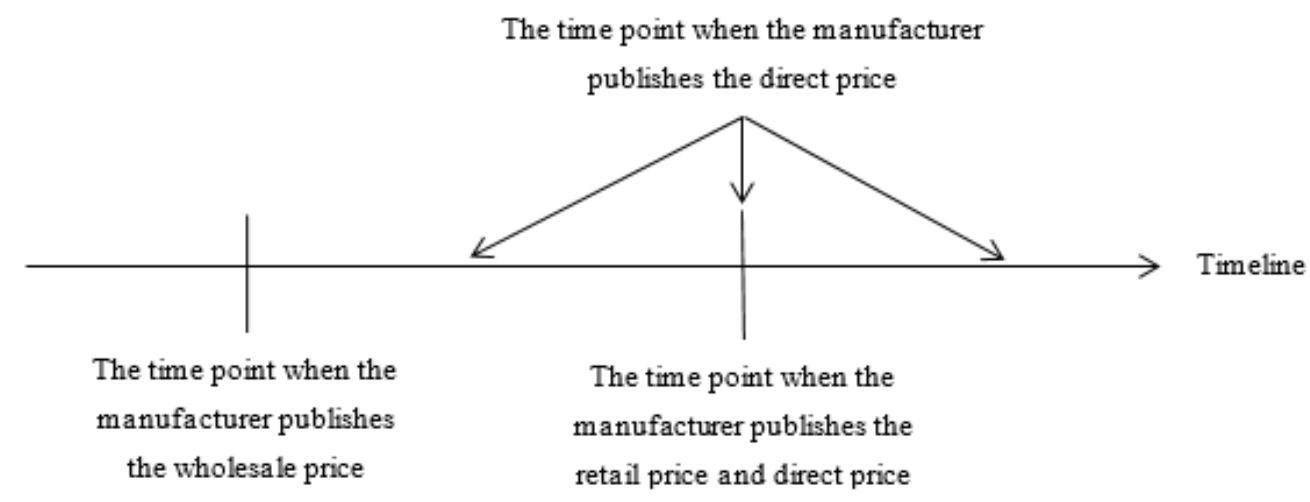

Fig. 2. Timeline 
A. The Stackelberg models of manufactures' announcement of direct price before retailers' announcing retail price and direct prices

For the situation that the manufacturers publish the direct price before retailers publishing the retail price and the direct price, and the two sides in a non-cooperative competitive state, retailers will adjust their price according to the manufacturers' price, in order to maximize profits. First calculate the derivations of $\mathrm{p}_{1}$ and $\mathrm{p}_{2}$ by formula (5), so that $\partial_{\pi} / \partial_{\mathrm{p}_{1}}=0$ and $\partial_{\pi} / \partial_{\mathrm{p}_{2}}=0$, and calculate $\mathrm{p}_{1}$ and $\mathrm{p}_{2}$ in that formula, we can get:

$$
\begin{aligned}
& \mathrm{p}_{1}^{*}=\frac{w}{2}+\frac{s_{2} \theta_{1} a+\beta \theta_{2} a+\beta^{2} p_{3}^{*}+s_{2} \beta p_{3}^{*}}{2 A} \\
& \mathrm{p}_{2}^{*}=\frac{w}{2}+\frac{s_{1} \theta_{2} a+\beta \theta_{1} a+\beta^{2} p_{3}^{*}+s_{1} \beta p_{3}^{*}}{2 A}
\end{aligned}
$$

Calculate formula (6), (7) in formula (4), and get the derivations of P3 and $\mathrm{w}$ in formula (4), let $\partial_{\Pi} / \partial_{\mathrm{p}_{3}}=0$ and $\partial_{\Pi} / \partial_{w}=0$,calculate $p_{3}$ and $\mathrm{w}$ in that formula, we can get:

$$
\begin{array}{r}
\mathrm{p}_{3}^{*}=\frac{[\mathrm{c}(-l-2 \beta)+k a] A+c\left(2 A s_{3}-T\right)-2 c \beta A+a[2(1-k) A+E]}{\left(T-2 A s_{3}\right)-2 A \beta} \\
w^{*}=\frac{c(L+2 \beta)\left(T-2 A s_{3}\right)+2 \beta\left[c\left(2 A s_{3}-T\right)-2 c A \beta+a(1-k) A+a E\right]}{2 \beta^{2} A-2 \beta L\left(2 A s_{3}-T\right) L}
\end{array}
$$

At this point, the manufacturer's profit is:

$$
\begin{aligned}
\Pi^{*} & \left.=\left(p_{3}^{*}-c\right)\left[(1-L) a-S_{3} p_{3}^{*}+\beta p_{1}^{*}+\beta p_{2}^{*}\right)\right] \\
& +\left(w^{*}-c\right)\left[L a-s_{1} p_{1}^{*}-s_{2} p_{2}^{*}+\beta\left(p_{1}^{*}+p_{2}^{*}+2 p_{3}^{*}\right)\right]
\end{aligned}
$$

\section{B. The Stackelberg model of manufacturers publishing direct prices at the same time when retailers publish retail prices and direct prices}

At this point, only the wholesale price can be referenced by the manufacturer and the retailer when formulating the optimal pricing strategy, and the wholesale price has been announced before. In this case, both sides can only formulate the corresponding retail price and the direct price according to the wholesale price to pursue the profit maximization. So we can get the derivation of P3 in formula (4), and derivations of $\mathrm{P} 1$ and $\mathrm{P} 2$ in formula (5), let $\partial_{\pi} / \partial_{\mathrm{p}_{1}}=0, \partial_{\pi} / \partial_{\mathrm{p}_{2}}=0$ and $\partial_{\Pi} / \partial_{\mathrm{p}_{3}}=0$, calculate $\mathrm{P} 1, \mathrm{P} 2, \mathrm{P} 3$ in that formula, we can get:

$$
\begin{aligned}
p_{1}^{* * *}= & \frac{w^{* *}}{2}+\frac{s_{2} \theta_{1} a+\beta \theta_{2} a}{2 A} \\
& +\frac{\left(\beta^{2}+s_{2} \beta\right)\left[\left(6 \beta w^{* *}-4 \beta c\right) A+2 A(1-k) a+E a+2 A s_{3}\right]}{2 A\left(2 A s_{3} T\right)}
\end{aligned}
$$

$$
\begin{aligned}
p_{2}^{* * *}= & \frac{w^{* *}}{2}+\frac{s_{1} \theta_{2} a+\beta \theta_{1} a}{2 A} \\
& +\frac{\left(\beta^{2}+s_{1} \beta\right)\left[\left(6 \beta w^{* *}-4 \beta c\right) A+2 A(1-k) a+E a+2 A s_{3}\right]}{2 A\left(2 A s_{3} T\right)}
\end{aligned}
$$

$$
p_{3}^{* *}=\frac{\left[\left(6 \beta w^{* *}-4 \beta c\right) A+2 A(1-k) a+E a+2 A s_{3}\right]}{2 A s_{3}-T}
$$

Put formula (11), (12) and (13) in formula (4), and calculate the derivation of $\mathrm{W}$ in formula (4), let $\partial_{\Pi} / \partial_{\mathrm{w}}=0$, we can get:

$$
\begin{aligned}
w^{* * *}= & \frac{c(L+2 \beta)\left(T-2 A s_{3}\right)+2 \beta\left[c\left(2 A s_{3}-T\right)-2 c A \beta+a(1-k) A+a E\right]}{2 \beta^{2} A-2 \beta\left(2 A s_{3}-T\right) L} \\
& -\frac{\beta^{3}(a-A c)}{2 s_{1} s_{2}\left(36 s_{1} s_{2} s_{3}+\beta^{3}\right)}
\end{aligned}
$$

At this point, the manufacturer's profit is:

$$
\begin{aligned}
\Pi^{* *} & \left.=\left(p_{3}^{* *}-c\right)\left[(1-L) a-S_{3} p_{3}^{* *}+\beta p_{1}^{* *}+\beta p_{2}^{* *}\right)\right] \\
& +\left(w^{* *}-c\right)\left[L a-s_{1} p_{1}^{* *}-s_{2} p_{2}^{* *}+\beta\left(p_{1}^{* *}+p_{2}^{* *}+2 p_{3}^{* *}\right)\right]
\end{aligned}
$$

C. The stackelberg model of the manufacturer publishing the direct price after the retailer releases the retail pricing and the direct price.

In this case, the manufacturer can determine the direct price of the channel on the basis of the wholesale price issued by the manufacturer before, as well as the retail price and the direct price issued by the retailer. So we should calculate the derivation of P3 in formula (4), we can get :

$p_{3}^{* * * *}=\frac{\left[2\left(w^{* * * *}-c\right) \beta+c(1-L) a+\beta\left(p_{1}^{* * * *}+p_{2}^{* * *}\right)+c s_{3}\right]}{2 s_{3}}$

Put the formula (16) in formula (5), and calculate the derivations of $\mathrm{P} 1, \mathrm{P} 2$ in formula $(5)$, let $\partial_{\pi} / \partial_{\mathrm{p}_{1}}=0$ and

$\partial_{\pi} / \partial_{\mathrm{p}_{2}}=0$, we can get:

$$
\begin{aligned}
& p_{1}^{* * * *}=\frac{2\left(\beta^{2}-s_{2} s_{3}-\beta s_{2}\right) A s_{3} w^{* * *}+B}{8 s_{1}^{2} s_{3}^{2}-2 s_{2} s_{3} \beta^{2}-\beta^{4}-7 s_{3} \beta^{3}-4 s_{3}^{2} \beta^{2}} \\
& p_{2}^{* * * *}=\frac{2\left(\beta^{2}-s_{1} s_{3}-\beta s_{1}\right) A s_{3} w^{* * * *}+B}{8 s_{2}^{2} s_{3}^{2}-2 s_{1} s_{3} \beta^{2}-\beta^{4}-7 s_{3} \beta^{3}-4 s_{3}^{2} \beta^{2}}
\end{aligned}
$$

Put the formula (16), (17) and (18) in formula (4), and calculate the derivation of $\mathrm{w}$ in formula (4), we can get :

$$
\begin{aligned}
w^{* * *}= & \frac{c(L+2 \beta)+2 \beta\left[c\left(2 A s_{3}-T\right)-2 c A \beta+a(1-k) A+a E\right]}{2 \beta^{2} A-2 \beta\left(2 A s_{3}-T\right) L} \\
& -\frac{s_{3} \beta^{3}(a-A c)}{2\left(\mathrm{~s}_{1}^{2} \mathrm{~s}_{2}^{2} \mathrm{~s}_{3}^{2}-5 s_{1} s_{2} s_{3} \beta^{3}+\beta^{6}\right)}
\end{aligned}
$$

At this point, the manufacturer's profit is:

$$
\begin{aligned}
\Pi^{* * * *} & \left.=\left(p_{3}^{* * *}-c\right)\left[(1-L) a-S_{3} p_{3}^{* * * *}+\beta p_{1}^{* * * *}+\beta p_{2}^{* * * *}\right)\right] \\
& +\left(w^{* * * *}-c\right)\left[L a-s_{1} p_{1}^{* * * *}-s_{2} p_{2}^{* * * *}+\beta\left(p_{1}^{* * * *}+p_{2}^{* * * *}+2 p_{3}^{* * * *}\right)\right]
\end{aligned}
$$

Among them: $A=s_{1} s_{2}-\beta^{2}$

$$
B=3 s_{3} a \beta^{2} K+\beta^{4}+s_{3}^{2} \beta^{2}-4 s_{3} \beta^{3}+s_{1} s_{2} s_{3} \beta
$$




$$
\begin{aligned}
& K=\theta_{1}+\theta_{2}, E=\left(\beta s_{1}+\beta^{2}\right) \theta_{2}+\left(\beta s_{2}+\beta^{2}\right) \theta_{1} \\
& L=2 \beta-s_{1}-s_{2}, T=2 \beta^{3}+s_{1} \beta^{2}+s_{2} \beta^{2}
\end{aligned}
$$

Comparing formula (10), (15) and (20), we can get

$$
\Pi^{*}>\Pi^{* *}>\Pi^{* * *}
$$

Thus, when the manufacturer and retailer in a noncooperative state, manufacturers announce the direct price before the retail price and the direct price announced by retailers, the manufacturers can achieve maximum profit. In the following research, it is supposed that manufacturers announce the direct price before the retail price and the direct price announced by retailers can achieve a balance, or that this strategy can make the multi-channel supply chain is in a steady state. Meanwhile, other pricing strategies, because of its' instability, will gradually be close to the strategy.

\section{CONCLUSION}

For the multi- supply chain model that the retailer in the traditional dual channel supply chain increases the direct channel, the paper studies the publishing time of the dominant manufacturer's direct channel price. Using the Stackelberg non-cooperative game theory and the delayed game theory, the paper proves the hypothesis of the manufacturer in three cases. This study shows that, by comparing the manufacturers' pricing strategy in three different situations from the manufacturer's point, that manufacturers publishing the direct price before the retailer announces the retail price and the direct price can maximize their own profits. The innovation of this paper is that the pricing strategy for pricing time such a multi-channel supply chain has not been proposed. The increase of new channels will inevitably lead to the conflict in the entire supply chain channel. As the dominant, the manufacturer must attach importance to the impact of new channels on the profitability of the original channels. The impact of the profit situation is the most intuitive result. What is worth exploring is the influence of other factors in the supply chain, including demand, price and so on. At the end, the paper provides the relevant theoretical basis for the manufacturers in the multi-channel supply chain structure when making the relevant pricing strategies.

\section{REFERENCES}

[1] Vol. N. "Price competition in a channel structure with a common retailer." Marketing Science, Vol. 10, No. 4, 1991, pp. 271-296.

[2] Hua, Guowei, S. Wang, and T. C. E. Cheng. "Price and lead time decisions in dual-channel supply chains." European Journal of Operational Research, Vol. 205, No. 1, 2010, pp. 113-126.

[3] Chiang W K,Chhajed D, Hess J D. "Direct marketing indirect profits: A strategic analysis of dual-channel supply chain design." Management science, Vol. 49, No. 1, 2003, pp. 1-20.

[4] Chiang, Wei Yu Kevin. "Supply chain dynamics and channel efficiency in durable product pricing and distribution." Manufacturing \& Service Operations Management, Vol. 14,No. 2, 2012, pp. 327-343.

[5] Tang, Christopher S. "A review of marketing-operations interface models: From co-existence to coordination and collaboration." International Journal of Production Economics, Vol. 125, No. 1, 2010, pp. 22-40.

[6] Ji Leilei, "Research on Retailer's dual channel closed loop supply chain coordination strategy." Technology and Innovation Management, Vol. 36, No. 2, 2015, pp. 200-205.

[7] Matsui, Kenji. "When should a manufacturer set its direct price and wholesale price in dual-channel supply chains?" European Journal of Operational Research, Vol. 258, No. 2, April. 2017, pp. 501-511.

[8] Dan Bin, Xu Guangye, Zhang Xumei. "Research on compensation strategy of dual channel supply chain coordination in e-commerce environment." Journal of Management Engineering, Vol. 26, No. 1, 2012, pp. 125-130.

[9] Gal-Or, Esther. "First mover and second mover advantages." International Economic Review, Vol. 26, No. 3, 1985, pp. 649-653. 